\title{
Examining Risk-Taking Behavior and Sensation Seeking Requirement in Extreme Athletes
}

\author{
Ali Agilonu ${ }^{1}$, Gulsum Bastug ${ }^{1}$, Tonguc Osman Mutlu ${ }^{1} \&$ Adem Pala $^{1}$ \\ ${ }^{1}$ Mugla Sitki Kocman Universtiy, Faculty of Sports Science, Mugla, Turkey \\ Correspondence: Adem Pala, Mugla Sitki Kocman Universtiy, Faculty of Sports Science, 48000, Mugla, Turkey. \\ Tel: 90-555-746-5861. E-mail: ademmpala@hotmail.com
}

Received: November 16, 2016

Accepted: December 31, 2016 Online Published: January 11, 2017

doi:10.5539/jel.v6n1p330

URL: http://dx.doi.org/10.5539/jel.v6n1p330

\begin{abstract}
Extreme sports are sport branches which include actions, adventures, risks and difficulties more rather than other sports. Special materials are used in sport branches such as surfing, kite surfing, sailing, snowboarding, paragliding, diving, mountaineering, motor sports and adrenaline release is more rather than in other sport branches. On the contrary, the situation for being eager to seek excitement and take risks with a view to having new experiences has been observed. It has been considered whether sensation seeking requirement and risk-taking behavior had effects upon each other. The aim of the study was to analyze sensation seeking and risk-taking behavior in extreme athletes. Total 101 extreme athletes including 31 females, 70 males with an age average of $22.03 \pm 6.77$ participated in the research. In order to determine athletes' sensation seeking levels, "Arnett Inventory of Sensation Seeking" developed by Arnett (1994) and in order to determine their risk-taking behavior, "Risk Involvement and Perception Scale" developed by Siegel et al. (1994) were used. In evaluation of research data, frequency analysis, independent $t$ test, in determination of relation between risk-taking and sensation seeking, correlation test were utilized.

In conclusion, significant differences were found in risk-taking behavior, sensation seeking requirement and gender variable among the extreme athletes. In the male athletes sensation seeking requirement and risk-taking behavior had higher averages than the female athletes. Among the extreme athletes, significant relations were determined between risk-taking behavior and sensation seeking requirement. When risk-taking behavior values were high, sensation seeking requirement values were regarded to be high.
\end{abstract}

Keywords: extreme athletes, risk taking behavior, sensation seeking requirement

\section{Introduction}

Sensation seeking requirement is described as a necessity for having different, new, complicated senses and experiences and a desire for social and physical risk-taking (Zuckerman, 1979). According to Arnett and Balle-Jensen (1993), as a tendency for searching and discovering new and intense experiences and according to Roberti (2004), as a concept based on genetic, bio-chemical, psycho-physiological and social factors, sensation seeking requirement is defined as well. When an individual makes decisions for taking risks, he creates a thinking process associated with possible results of any behavior. Adolescents and adults also use similar ways in decision-making process, but they have significant differences in risk-taking behavior depending on factors such as experiences, prejudices, judgements, social pressures (Keating, 2004). When adolescents are together with their peers performing risk behaviors, this also leads them to display extreme behaviors in next period (Arnett, 1992; Goldstein et al., 2005). Since identification degrees and similarities to friends increase peer effect on adolescents, close friends are more effective on adolescents rather than general friend groups (Jaccard, Blanton, \& Dodge, 2005). Greene et al. (2000) stated that risk-taking behavior was associated with an individual's personal characteristics. Human beings bravely searched for activities with risks of fear and death available at the most extreme points to be stronger and greater (Brymer \& Oades, 2009). Athletes sometimes want to have experiences at the most extreme points by trying diverse pursuits except for traditional sport branches (Coffey, 2008). Extreme sports was defined as "activities are highly possible to result in death when these are managed, in contrast to injury" mistakenly by Brymer (2005). Free climbing, solo rope climbing, extreme mountaineering, waterfall kayaking, deep water diving, extreme skiing, BASE (building, antenna, span, earth) jumping, big wave surfing, and wing-suit flying were given as general examples of extreme sports by Brymer and Oades (2009). 
Extreme sports such as sky diving, altitude mountain climbing, rock climbing, whitewater rafting, motor-cycling, skydiving, and paragliding are among the group of sports associated with high risks (Davis-Berman \& Berman, 2002; Demirhan, 2005; Martha et al., 2009). In recent years, risk-focused, adventure-related nature sports have been performed with increasing popularity and risk perception in extreme sports has been researched in recent times (Pedersen, 1997; Vagias et al., 2005). A study concerning risky sports indicated that personal characteristics such as extraversion and openness were at high levels in individuals engaged in surfing, climbing and diving as risky sports, conscientiousness and neuroticism (a personal characteristic defined as tension and emotional imbalance were at low levels (Tok, 2011). Risk-taking behaviors in extreme sports such as skydiving, surfing and mountaineering are often perceived as different issues in various fields (e.g., gambling, reckless driving or sexual behavior) because of their greater social acceptability (Castanier, Le Scanff, \& Woodman, 2010). In recent times, although the interest of extreme sports has increased day by day, social media has stand out as the mean of dissemination. In terms of extreme sports, using communication technologies has provided to more people to access visual and audible information about extreme sports rapidly within communication by means of internet (Goksel \& Serarslan, 2015). Within this context, it has been thought that communication among extreme sportsmen/sportswomen on social media will also contribute to the awareness of extreme sports (Goksel \& Serarslan, 2016). Cliff jumping, bungee jumping, altitude mountain climbing, rock climbing, parachute jumping are rated as five most risky sports by female and male university students. As males regard motor sports to be more attractive than females, females consider land and water sports to be more attractive (Demirhan et al., 2014).

Recalling excitement and risk taking feelings at the most extreme points, performing extraordinary sports than common sports by other people, having different wishes and desires are represented as extreme sports. More excitement, more risk factors, even the danger of death because of the smallest fault are possible as opposed to other sports for people who would sooner do these sports. While some people opt for the least dangerous sports with low risk factors, some people prefer sports including excitement, risk, danger. Some differences draw attention in these types of people eager to experience excitement, risk, danger feelings. The relation between sensation seeking requirement and risk taking behavior has been considered to make contributions to next researches in this field. In the light of this information, the aim of the research was to analyze risk taking behavior and sensation seeking requirement in extreme athletes.

\section{Method}

\subsection{The Method of the Study}

The study was conducted with relational scanning model, which is one of the general scanning models. "Scanning Models are the research approaches that aim to describe an existing or past situation as is" (Karasar, 2000). "Relational scanning models aim to determine the existence or the level of the co-variation between two or more variables" (Karasar, 2000).

\subsection{The Universe and the Sampling of the Study}

Total 101 extreme athletes including 31 females, 70 males, having an age average of $22.03 \pm 6.77$ participated in the research. These 101 extreme athletes involved 50 persons in Muğla Gökova Gulf and Fethiye Area, 51 persons from different countries available via internet. The participants' extreme sport branches were associated with surfing, kite surfing, sailing, snowboarding, paragliding, diving, mountaineering, motor sports.

\subsection{Data Collection Tool}

To determine athletes' sensation seeking requirement, "Arnett Inventory of Sensation Seeking" designed by Arnett (1994) and to determine their risk perception, "Risk Involvement and Perception Scale" designed by Siegel et al. (1994) were used. The data were collected with face to face meeting and questionnaires filled out by participants.

Arnett Inventory of Sensation Seeking (AISS); Arnett Inventory of Sensation Seeking (Arnett, 1994) is an instrument that measures the individuals' level of sensation seeking. AISS is a 4-point Likert-type inventory that consists of 20 items (e.g., "I can see how interesting it would be to marry someone from a foreign country") and has five reverse items (e.g., "If I have to wait in a long line, I'm usually patient about it"). The maximum score that can be obtained from the inventory is 80 , and the minimum one is 20 . The items are grouped in the two subscales that named as novelty and intensity. While items $1,3,5,7,9,11,13,15,17,19$ take part in the novelty subscale, items $2,4,6,8,10,12,14,16,18,20$ are included in the intensity component of the AISS. In his study with adolescents, Arnett (1994) found that internal reliability $(\alpha)$ of the total scale was $.70, .64$ for the intensity, and .50 for the novelty subscale. AISS has been used in several studies within Turkish samples (Sümer, 2000; 
Sümer \& Özkan, 2002; Ayvaşı, Sümer, \& Er, 2005). These studies have been conducted on adult samples (drivers). For example, in Sümer's (2003) study, AISS factor structure with Multidimensional Self-Destructiveness Scale (MSS) developed by Persing and Schick (1999) was examined in adult male drivers and it was found that 19 items of AISS together with the five items of MSS yielded three interpretable components, representing the two subscales of the AISS and MSS, explaining 34\% of the variance. For the five items representing the novelty subscale, $19 \%$ of the variance was explained, and for the eight items of the intensity subscale $8 \%$ of the variance was given. Some items did not load any of the factors or highly cross-loaded on at least two components, thus they were excluded from the factor analysis. Besides, one of the items that takes part in the original form of the AISS, "I don't like extremely hot and spicy foods" was initially excluded from the inventory because of common use of spices in the Turkish foods. In that study internal consistency coefficients $(\alpha)$ were acceptable; for novelty .62, and for intensity .68. In another example, Ayvaşık, Er and Sümer (2005) examined the factor structure of the AISS together with the five items of the MSS again. The results of the study indicated that a single factor solution with 19 items represented a better harmonisation to the relevant data. Besides, alpha correlation coefficient was found to be 0.85 .

Modified Risk Involvement and Perception Scale (M-RIPS); Risk Involvement and Perception Scale developed by Siegel et al. (1994) contains 18 items and four subscales. The four subscales are involvement, intentions, perceived risks, and perceived benefits. In another study, Parsons et al. (1997) revised the scale and one of the items, "driving car" was excluded from the RIPS. The original RIPS is a 9-point Likert type scale and the same set of 17 items takes part in each of the subscales with appropriate instructions for those subscales. Each of the 17 items depicts a low, moderate or higher risky behavior that might be displayed by an adolescent as a self-destructive or destructive behavior such as "smoking", or "having sex". The possible maximum score obtained from the scale is 153 and minimum is 17. The higher scores show that risk is high, and individuals' involvement of risk-taking behaviors is frequent. The construct and content validity of involvement subscale of Risk Involvement and Perception Scale includes six factors (alcohol, illegal drugs, sexual behaviors, stereotypic male behaviors, socially acceptable behaviors, and imprudent behaviors) (Parsons et al., 1997; Rolison \& Scherman, 2003). These six factors accounted for $66 \%$ of the variance in reported involvement (Rolison \& Scherman, 2003). For the involvement subscale, while the test-retest reliability coefficient was 0.86 , the alpha internal reliability coefficient was regarded as .72 (Ben-Zur \& Reshef-Kfir, 2003). The subscale (Involvement) of the Risk Involvement and Perception Scale was adapted to Turkish culture by the researcher in the present study. The involvement subscale intends to measure the frequency of involvement in the last three months with given 17 behaviors.

\subsection{The Analysis of Data}

The data obtained from the scale in the research were analyzed by means of SPSS 21.0 statistical software program. In the research, frequency analysis, independent $t$ test, in determination of relation between risk-taking and sensation seeking, correlation test were utilized.

\section{Results}

Table 1. Demographics about participants

\begin{tabular}{clll}
\hline Variables & Frequency & Percent \\
\hline \multirow{2}{*}{ Gender } & Female & 31 & 30.7 \\
& Male & 70 & 69.3 \\
& University & 60 & 59.4 \\
Education Background & Graduate & 24 & 23.8 \\
& High School & 17 & 16.8 \\
& $1000-1500$ & 16 & 15.8 \\
Income Status & $1500-2000$ & 13 & 12.9 \\
& $2000-3000$ & 14 & 13.9 \\
& 3000 and over & 58 & 57.4 \\
\hline
\end{tabular}


As seen at Table 1, 30.7\% of the research participants were females, $69.3 \%$ of them were males, $59.4 \%$ were university graduates, $57.4 \%$ of them had an income level of 3000 and over it.

Table 2. Analysis of risk taking behavior and sensation seeking requirement in accordance with gender variable in extreme athletes

\begin{tabular}{|c|c|c|c|c|c|c|}
\hline & Gender & $\mathrm{N}$ & Mean & Std. Deviation & $\mathrm{t}$ & $\mathrm{p}$ \\
\hline \multicolumn{7}{|l|}{ Risk-Taking Behavior } \\
\hline \multicolumn{7}{|l|}{ Sub-Dimensions } \\
\hline \multirow[t]{2}{*}{ Low Risk-Taking } & Male & 70 & 34,58 & 8,09 & & \\
\hline & Female & 31 & 32,90 & 6,29 & 1.13 & 0.26 \\
\hline \multirow[t]{2}{*}{ High Risk-Taking } & Male & 70 & 9,00 & 3,13 & & \\
\hline & Female & 31 & 8,22 & 1,43 & 1.70 & 0.09 \\
\hline \multirow{2}{*}{$\begin{array}{l}\text { Risk-Taking Behavior } \\
\text { (total point) }\end{array}$} & Male & 70 & 62,48 & 13,62 & & \\
\hline & Female & 31 & 57,70 & 9,86 & 1.98 & $0.04 *$ \\
\hline \multicolumn{7}{|l|}{ Sensation-Seeking Requirement } \\
\hline \multicolumn{7}{|l|}{ Sub-Dimensions } \\
\hline \multirow[t]{2}{*}{ Intensity } & Male & 70 & 26,52 & 3,86 & & \\
\hline & Female & 31 & 25,00 & 4,13 & 1.75 & 0.08 \\
\hline \multirow[t]{2}{*}{ Novelty } & Male & 70 & 26,58 & 3,29 & & \\
\hline & Female & 31 & 25,70 & 3,34 & & \\
\hline \multirow{2}{*}{$\begin{array}{l}\text { Sensation-Seeking Requirement } \\
\text { (total point) }\end{array}$} & Male & 70 & 56,27 & 5,33 & 1.21 & 0.22 \\
\hline & Female & 31 & 53,77 & 4,80 & 2.32 & $0.02 *$ \\
\hline
\end{tabular}

$* \mathrm{p} \leq 0.05$.

As seen at Table 2, a significant relation was seen between risk taking behavior and gender variable in the extreme athletes. As risk perception had an average of $(62,48+13.62)$ in the males, it had an average of $(57.70+$ $9.86)$ in the females. Furthermore, a significant relation was found in sensation seeking requirement and gender variable. As sensation seeking requirement had an average of $(56.27+5.33)$ in the males, it had an average of $(53.77+4.80)$ in the females. Risk perception and sensation seeking requirement in the males performing extreme sports had higher values than the female athletes.

Table 3. Analysis of relation between risk taking behavior and sensation seeking requirement in extreme athletes

\begin{tabular}{|c|c|c|c|c|c|c|}
\hline \multicolumn{7}{|l|}{ Correlations } \\
\hline & & 1 & 2 & 3 & 4 & 5 \\
\hline \multirow[t]{3}{*}{ 1. Gender } & Pearson Correlation & 1 &,- 174 &,- 103 &,- 131 &,$- 219^{*}$ \\
\hline & Sig. (2-tailed) & &, 082 &, 307 & ,193 &, 028 \\
\hline & $\mathrm{N}$ & 101 & 101 & 101 & 101 & 101 \\
\hline 2. Risk-Taking & Pearson Correlation &,- 174 & 1 &, $943^{* *}$ &, $752^{* *}$ & $241^{*}$ \\
\hline total point & Sig. (2-tailed) & ,082 & &, 00 &, 00 &, 015 \\
\hline
\end{tabular}




\begin{tabular}{|c|c|c|c|c|c|c|}
\hline & $\mathrm{N}$ & 101 & 101 & 101 & 101 & 101 \\
\hline \multirow[t]{3}{*}{ 3. Low Risk-Taking } & Pearson Correlation &,- 103 &, $943^{* *}$ & 1 &, $612^{* *}$ &, $204^{*}$ \\
\hline & Sig. (2-tailed) &, 307 &, 00 & &, 00 &, 041 \\
\hline & $\mathrm{N}$ & 101 & 101 & 101 & 101 & 101 \\
\hline \multirow[t]{3}{*}{ 4. High Risk-Taking } & Pearson Correlation &,- 13 &, $752^{* *}$ &, $612^{* *}$ & 1 &, 080 \\
\hline & Sig. (2-tailed) & ,193 &, 00 &, 00 & & ,426 \\
\hline & $\mathrm{N}$ & 101 & 101 & 101 & 101 & 101 \\
\hline \multirow[t]{2}{*}{ 5.Sensation-Seeking Requirement } & Pearson Correlation &,$- 22^{*}$ &, $241^{*}$ &, $204^{*}$ &, 080 & 1 \\
\hline & Sig. (2-tailed) &, 028 & ,015 &, 041 & ,426 & \\
\hline ( total point ) & $\mathrm{N}$ & 101 & 101 & 101 & 101 & 101 \\
\hline
\end{tabular}

*. Correlation is significant at the 0.05 level (2-tailed).

**. Correlation is significant at the 0.01 level (2-tailed).

As seen at Table 3, meaningful relations were found in risk perception, low risk perception, sensation seeking requirement and gender variable in the extreme athletes $(\mathrm{p}<0.05$ and $\mathrm{p}<0.01)$. And a meaningful relation was observed in risk taking behavior and sensation seeking requirement.

\section{Conclusion and Discussion}

Within the study aimed at risk taking behavior and sensation seeking requirement in the extreme athletes; Of the research participants $30.7 \%$ were females, $69.3 \%$ was males, $59.4 \%$ of them were university graduates, 57.4 of them had an income of $3000 \mathrm{TL}$ and over it (Table 1). Ones engaged in extreme sports were mostly university graduates and had a high level of income, these estimations were recognizable. The reason for high levels of income and education background in extreme sports is related with factors such as carrying out training process of these sports under difficult requirements, in different natural conditions, utilizing special items rather than other sport branches, using expensive materials.

A significant relation was found between risk taking behavior and gender variable in the extreme athletes. A significant relation was also found between sensation seeking requirement and gender variable. Risk perception and sensation seeking requirement had higher values in the males engaged in extreme sports than the female athletes (Table 2). The reason for high values in risk perception and sensation seeking requirement of the males was associated with upbringing style of male and female children by families, socio-economic and socio-cultural items. A research focused on the analysis of excitement and adventure seeking in accordance with gender variable, revealed significant differences and determined that the male subjects' sensation seeking values were higher than the female subjects (Siyez, 2014). In another study examining university students' risk and attractiveness perceptions about extreme sports, their risk perception, gender and previous participation in these kinds of sports varied from each other (Demirhan et al., 2014). The paper titled with "Sensation Seeking in the Community: Sex, Age and Socio-Demographic Comparisons on a Representative German Population Sample" demonstrated that the feature of excitement seeking differed from age and gender, the males' points were higher than the females. Higher points were generally observed in the males at all age groups than the females (Roth, Schumacher, \& Brahler, 2005). Risk taking behavior was investigated in various age groups, high school students and university students were compared in terms of risk taking behaviors; risk taking behaviors were usually considered to increase with ages until university level, then they decreased as well. In terms of gender, the males showed risk taking behavior more than the females (Bayar \& Sayıl, 2005).

Significant relations were observed in risk taking behavior, low risk taking, sensation seeking requirement and gender variable in the extreme athletes. Also, a meaningful relation was found in risk taking behavior and sensation seeking requirement. When risk taking behavior values arose, sensation seeking requirement values went up (Table 3). Rolison and Scherman (2003) studied excitement seeking, focus of control, perceived risk, perceived benefits, risk involvement, peer effect and perceived peer involvement, social adorability and reactions to risky behavior scenario among 196 adolescents aged between 18 and 21. The research indicated that excitement seeking, perceived peer involvement and perceived benefit affected risk involvement. When 
personality and risk taking behavior were analyzed in ones engaged in rafting and scuba diving, there was a meaningful relation in risk taking behavior and adventure seeking. Personality characteristics which had impacts on risk taking behavior, were to be outgoing, frank and conscious (Leea \& Tsengb, 2015). In a research about personality, self-competence and risk taking, significant relations were determined between self-competence, neuroticism (a personality characteristic defined as tension and emotional imbalance), consciousness and risk taking (Merritt \& Tharp, 2013). These research findings support our study.

In conclusion, significant relations were found between risk taking behavior, sensation seeking requirement and gender variable in the extreme athletes. The male athletes had higher averages than the female athletes in terms of sensation seeking requirement and risk taking behavior. A significant relation was found in risk taking behavior and sensation seeking requirement in the extreme athletes. When risk taking behavior values increased, sensation seeking requirement values arose as well.

\section{References}

Arnett, J. (1992). Reckless behavior in adolescence: A developmental perspective. Developmental Review, 12, 339-373. https://doi.org/10.1016/0273-2297(92)90013-R

Arnett, J. J., \& Balle, J. (1993). Cultural Bases of Risk Behavior: Danish Adolescent. Child Development, 64, 1842-1855. https://doi.org/10.2307/1131473

Arnett, J. (1994). Sensation seeking: A new conceptualization and a new scale. Personality and Individual Differences, 16(2), 289-296. https://doi.org/10.1016/0191-8869(94)90165-1

Ayvasık, H. B., Er, N., \& Sümer, N. (2005). Traffic violations and errors: The effects of sensation seeking and attention. Paper presented at 3rd International Driving Symposium on Human Factor in Driver Assessment, Training, and Vehicle Design, Rockport, MA.

Bayar, N., \& Sayll, M. (2005). Brief report: Risk taking behaviors in a non-western urban adolescent sample. Journal of Adolescence, 28, 671-676. https://doi.org/10.1016/j.adolescence.2005.01.010

Brymer, E. (2005). Extreme dude: A phenomenological exploration into the extreme sport experience (Doctoral dissertation). Available from the University of Wollongong Library, New South Wales, Australia.

Brymer, E., \& Oades, L. (2009). Extreme sports: A positive transformation in courage and humility. Journal of Humanistic Psychology, 49, 114-126. https://doi.org/10.1177/0022167808326199

Ben-Zur, H., \& Reshef-Kfir, Y. (2003). Risk taking and coping strategies among Israeli adolescents. Journal of Adolescence, 26(3), 255-265. https://doi.org/10.1016/S0140-1971(03)00016-2

Castanier, C., Le Scanff, C., \& Woodman, T. (2010). Who Takes Risks in High-Risk Sports? A Typological Personality Approach. Research Quarterly for Exercise and Sport, 81(4), 478-484. https://doi.org/10.1080/02701367.2010.10599709

Coffey, M. (2008). Explorers of the infinite: The secret spiritual lives of extreme athletes-And what they reveal about near-death experiences, psychic communication, and toughing the beyond. New York, NY: Jeremy P. Tarcher/Penguin.

Davis-Berman, J., \& Berman, D. (2002). Risk and Anxiety in Adventure Programming. Journal of Experiential Education, 25, 305-310. https://doi.org/10.1177/105382590202500209

Demirhan, G. (2005). Mountaineers' risk perception in outdoor-adventure sports: A study of sex and sports experience. Perceptual and Motor Skills, 100, 1155-1160. https://doi.org/10.2466/PMS.100.4.1155-1160

Demirhan, G., Aşc1, H., Kangalgil, M., \& Saraçbaş1, O. (2014). Perception of Risk and Attractiveness of Extreme Sports among Turkish University Students. Hacettepe Journal of Sport Sciences, 25(1), 11-22.

Greene, K., Krcmar, M., Walters, L. H., Rubin, D. L., Hale, J., \& Hale, L. (2000). Targeting Adolescent Risk Taking Behaviors: The Contributions of Egocentrism and Sensation Seeking. Journal of Adolescence, 23, 439-461. https://doi.org/10.1006/jado.2000.0330

Goksel, A. G., \& Serarslan, M. Z. (2015). Public relations in sports clubs: New media as a strategic corporate communication instrument. International Journal of Physical Education, Sports and Health, 2(2), 275-283.

Goksel, A. G., \& Serarslan, M. Z. (2016). Evaluating the Corporate Communication Strategies of Sports Clubs in the New Media. International Journal of Advance Research (IJAR), 4(8), 607-614. http://dx.doi.org/10.21474/IJAR01/1253 
Goldstein, S. E., Davis-Kean, P. E., \& Eccles, J. S. (2005). Parents, peers, and problem behavior: A longitudinal investigation of the impact of relationship perceptions and characteristics on the development of adolescent problem behavior. Developmental Psychology, 41, 401-413. https://doi.org/10.1037/0012-1649.41.2.401

Jaccard, J., Blanton, H., \& Dodge, T. (2005). Peer influences on risk behavior: An analysis of the effects of a close friend. Developmental Psychology, 41, 135-147. https://doi.org/10.1037/0012-1649.41.1.135

Keating, D. P. (2004). Cognitive and Brain Development. In Handbook of Adolescent Psychology (2. Bask ). New York: Wiley. https://doi.org/10.1002/9780471726746.ch3

Leea, T. H., \& Tsengb, C. H. (2015). How personality and risk-taking attitude affect the behavior of adventure recreationists. Tourism Geographies, 17(3), 307-331. https://doi.org/10.1080/14616688.2014.1000955

Martha, C., Sanchez, X., \& Gomà-i-Freixanet, M. (2009). Risk perception as a function of risk exposure amongst rock climbers. Psychology of Sport and Exercise, 10, 193-200. https://doi.org/10.1016/j.psychsport.2008.07.004

Merritt, C. J., \& Tharp, I. J. (2013). Personality, self-efficacy and risk-taking in parkour (free-running). Psychology of Sport and Exercise, 14, 608-611. https://doi.org/10.1016/j.psychsport.2013.03.001

Parsons, J. T., Siegel, A. W., \& Cousins, J. H. (1997). Late adolescent risk-taking: Effects of perceived benefits and perceived risks on behavioral intentions and behavioral change. Journal of Adolescence, 20(4), 381-392. https://doi.org/10.1006/jado.1997.0094

Pedersen, D. M. (1997). Perceptions of high risk sports. Perceptual and Motor Skills, 85, 756-758. https://doi.org/10.2466/PMS.85.6.756-758

Persing, C. R., \& Schick, C. (1999, June). Development and validation of a Multidimensional Self-Destructiveness Scale (MSS) to assess maladaptive and risky behaviors and beliefs in young adults. Paper presented at the meeting of the Pennsylvania Psychological Association, Valley Forge, PA.

Roberti, J. W. (2004). A review of behavioral and biological correlates of sensation seeking. Journal of Research in Personality, 38, 256-279. https://doi.org/10.1016/S0092-6566(03)00067-9

Rolison, M., \& Scherman, A. (2003). College Student Risk-Taking from Three Perspectives. Adolescence, 38(152), 689-703.

Roth, M., Schumacher, J., \& Brahler, E. (2005). Sensation seeking in the community: Sex, age and sociodemographic comparisons on a representative German population sample. Personality and Individual Differences, 39(7), 1261-1271. https://doi.org/10.1016/j.paid.2005.05.003

Siegel, A. W., Cousins, J. H., Rubovits, D. S., Parsons, J. T., Lavery, B., \& Crowley, C. L. (1994). Adolescents' perceptions of the benefits and risks of their own risktaking. Journal of Emotional and Behavioral Disorders, 2(2), 89-98. https://doi.org/10.1177/106342669400200203

Siyez, M. D. (2014). Gender and Sensation Seeking as Predictor Variables of Problematic Internet Use by High School Students, Turkish Green Crescent Society. Addicta: The Turkish Journal on Addictions, 1(1), 78-97.

Sümer, N., \& Özkan, T. (2002). Sürücü davranışları, becerileri, bazı kişilik özellikleri ve psikolojik belirtilerin trafik kazalarındaki rolleri. Psikoloji Dergisi, 17(50), 1-26.

Sümer, N. (2003). Personality and behavioral predictors of traffic accidents: Testing a contextual mediated model. Accident Analysis and Prevention, 35(6), 949-964. https://doi.org/10.1016/S0001-4575(02)00103-3

Tok, S. (2011). The Big Five Personality Traits and Risky Sport Participation. Social Behavior and Personality: An International Journal, 39(8), 1105-1111. https://doi.org/10.2224/sbp.2011.39.8.1105

Vagias, W., Morais, D., \& Dziubek, D. (2005). The role of risk perception in a one-day wilderness whitewater rafting trip. Northeastern Recreation Research Symposium. USDA Forest Service Newtown Square, PA.

Zuckerman, M. (1979). Sensation seeking: Beyond the optimal level of arousal. Hillsdale, NJ: Lawrence Erlbaum.

\section{Copyrights}

Copyright for this article is retained by the author(s), with first publication rights granted to the journal.

This is an open-access article distributed under the terms and conditions of the Creative Commons Attribution license (http://creativecommons.org/licenses/by/4.0/). 